\title{
Prognosis and Treatment of Idiopathic Facial (Bell's) Palsy
}

\author{
D. TAVERNER, M.D., F.R.C.P. ; F. KEMBLE,* M.D., M.R.C.P. ; S. B. COHEN, M.B., CH.B.
}

Brit. med.9., 1967, 4, 581-582

Previous reports from this department based on controlled clinical trials (Peiris and Miles, 1965; Taverner et al., 1966) have described methods for the early establishment of an accurate prognosis in idiopathic facial palsy and for the reduction in the incidence of denervation, with permanent sequelae, in this common condition. The present communication describes our experience of the use of these two methods in the routine management of facial palsy in the two years following the controlled trials. The results support the claims previously made, and we are now confident that these methods should be introduced into routine medical practice.

\section{Material and Methods}

All patients attending the department of electromyography in the 23 months following the conclusion of the previous study (Taverner et al., 1966) who were suffering from their first attack of idiopathic facial paralysis of not more than five days' duration are included. It was laid down that patients known to be in early pregnancy or to be suffering from diabetes mellitus, severe hypertension, or active peptic ulceration were to be excluded. Four patients were affected. The criteria for diagnosis were the same as those previously used (Taverner, 1955). The patients were allocated to treatment or observation groups on the basis of the threshold to anodal galvanic stimulation of the tongue by the method of electrogustometry (Krarup, 1958 ; Peiris and Miles, 1965). Treated patients were given five daily intramuscular injections of 80 units of adrenocorticotrophic hormone (A.C.T.H. gel), then 60, 40, 20, and 10 units on successive days. In $26 \%$ of the cases the injections were given in the outpatient department of the General Infirmary at Leeds. The remainder were given by the patients' general practitioners or by the district nurse. Some patients were examined electromyographically as described by Langworth and Taverner (1963).

At least three months after the onset of paralysis the final evaluation was made on clinical grounds, and patients with evidence of denervation were followed until no further improvement could be detected. In all except a few very mild cases each patient was seen by more than one observer. Two patients failed to reattend and have been excluded. Three others defaulted from the final assessment, but a reasonable conclusion seemed possible by combining the last clinic record with a report from the family doctor.

Clinical assessment of function in the facial muscles was estimated in terms of a percentage of the normal function of the orbicularis oris, orbicularis oculi, and frontalis muscles on the unaffected side. The results were classified as complete recovery or denervation. Denervation was recorded in the presence of any permanent defect of voluntary movement or any degree of associated movement, however slight.

\section{Results}

A study was made of 383 consecutive patients with idiopathic facial palsy of not more than five days' duration. Two de-

\footnotetext{
Departments of Electromyography and Medicine, The General Infirm-

* Present address : Department of Neurology, Queen Elizabeth Hospital, Birmingham 15.

faulted-one treated and one observed-leaving 381 for analysis (Table I). There were 191 females, mean aged 42.4 years, and 190 males, mean age 40.1 years.

TABLE I.-Age and Sex Distribution of 381 Consecutive Patients With

\begin{tabular}{|c|c|c|c|c|c|c|}
\hline \multirow{2}{*}{\multicolumn{2}{|c|}{ Category }} & \multicolumn{2}{|r|}{ Males } & \multicolumn{2}{|c|}{ Females } & \multirow{2}{*}{ Total } \\
\hline & & No. & Age & No. & Age & \\
\hline $\begin{array}{l}\text { Treated } \\
\text { Untreated } \\
\text { Whole group }\end{array}$ & $\because$ & $\begin{array}{l}116 \\
74 \\
190\end{array}$ & $\begin{array}{c}42 \cdot 1(10-77) \\
37 \cdot 0(4-73) \\
40 \cdot 1\end{array}$ & $\begin{array}{l}100 \\
91 \\
191\end{array}$ & $\begin{array}{c}42 \cdot 8(10-77) \\
41 \cdot 8(2-83) \\
42 \cdot 4\end{array}$ & $\begin{array}{l}216 \\
165 \\
381\end{array}$ \\
\hline
\end{tabular}

Prognosis.-Satisfactory normal responses to the anodal galvanic threshold test were obtained in 165 patients. The threshold was less than $10 \mu \AA$, and there was less than $5 \mu \AA$ difference between the two sides. The remaining patients were unable to co-operate, were heavy smokers with high thresholds, or had large differences in threshold between the two sides. They were treated with A.C.T.H. gel because of the risk of denervation. The sex and age distribution in the two groups was essentially the same (Table I). Of the 165 untreated patients $153(93 \%)$ recovered completely, as predicted, and 12 underwent denervation, only two seriously (Table II). The 10 with more than $70 \%$ recovery of function were fully satisfied with the outcome and considered themselves cured. Six of these 10 patients recovered more than $90 \%$ of normal power, and previous denervation was revealed by trivial flickers of associated movement. Retrospective analysis of the clinical records of the two patients with moderate to severe denervation showed that both had admitted subjective disturbance of taste when first seen. The more severely affected had also described hyperacusis and had later developed a significant difference in anodal galvanic threshold between the two sides.

Taвle II.-Outcome in the 12 Patients Who Developed Denervation Among the 165 Untreated Patients

\begin{tabular}{|c|c|c|c|c|c|c|}
\hline $\begin{array}{l}\text { Degree of recovery } \\
\text { No. of patients }\end{array}$ & 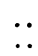 & $\ddot{x}$ & 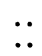 & $\begin{array}{l}<30 \% \\
1(8 \%)\end{array}$ & $\begin{array}{c}30-70 \% \\
1(8 \%)\end{array}$ & $\begin{aligned}>70 \% \\
10 *(84 \%)\end{aligned}$ \\
\hline
\end{tabular}

- Six of these patients recovered more than $90 \%$ of their normal function.

Treatment.-Of 216 patients treated with intramuscular injections of A.C.T.H. gel $178(82.5 \%)$ recovered completely and 38 developed denervation. Only 11 of the latter were affected to a moderate or severe degree (Table III); 27 were only slightly affected and considered themselves cured, and 14 of them recovered over $90 \%$ of normal function.

\begin{tabular}{|c|c|c|c|c|c|c|}
\hline $\begin{array}{l}\text { Degree of recovery } \\
\text { No. of patients .. }\end{array}$ & $\ddot{0}$ & $\ddot{\prime}$ & $\ddot{*}$ & $\begin{array}{l}<30 \% \\
6(15 \%)\end{array}$ & $\begin{array}{l}30-70 \% \\
5(13 \%)\end{array}$ & $\begin{aligned} 27 * 70 \% & (72 \%)\end{aligned}$ \\
\hline
\end{tabular}

Overall Outcome.-The results can best be illustrated by contrasting them with the null hypothesis that neither the prognostic testing nor the treatment had any influence whatever on the outcome. In a series of controlled therapeutic trials over many years we have repeatedly found that the proportion of unselected patients with idiopathic facial palsy developing denervation, using the very strict criteria here applied, is very 
close to $40 \%$ (Taverner, 1954 ; Mosforth and Taverner, 1958 ; Langworth and Taverner, 1963 ; Fearnley et al., 1964 ; Taverner et al., 1966). Taverner (1959) studied 164 successive patients with denervation and found less than $30 \%$ recovery in $38 \%, 30-70 \%$ recovery in $23 \%$, and over $70 \%$ recovery in $39 \%$.

In the present inquiry 381 patients were studied. In all, 50 $(13 \%)$ of them developed denervation in contrast to the 150 $(40 \%)$ that might have been expected. In addition, the degree of denervation was much less severe than could have been expected-a "shift to the right" (Table IV). The proportion of patients with severe denervation-that is, less than $30 \%$ of return of function-has fallen from $15 \%$ to $1.8 \%$.

TABLE IV.-Observed Outcome in 381 Consecutive Patients with Idiopathic Facial Palsy Compared with the Expected Result (See Text)

\begin{tabular}{cccc|c|c|c}
\multicolumn{3}{r}{ Degree of Recovery: } & $<30 \%$ & $30-70 \%$ & $>70 \%$ \\
\hline Expected.. &.. &. &. & $57(15 \%)$ & $34(9 \%)$ & $61(16 \%)$ \\
Observed.. &.. &.. &. & $7(1.8 \%)$ & $6(1.6 \%)$ & $37(10 \%)$
\end{tabular}

Side-effects.-Two patients complained of dyspepsia suggestive of peptic ulceration, and one of them probably bled fairly severely. Both recovered spontaneously and no permanent ill effects were observed.

\section{Discussion}

The method of anodal galvanic testing provides a means of selecting those patients with idiopathic facial palsy who are going to recover completely, with an accuracy of nearly $95 \%$. Its reliability can be increased by noting those patients with a normal threshold who admit to subjective disturbance of taste or to hyperacusis. Daily testing of the threshold will increase its accuracy still further. The importance of the test lies in the fact that it justifies the omission of A.C.T.H. gel therapy from a group of patients who do not need it. The converse proposition, that patients with an abnormal galvanic threshold will develop denervation, is not strictly true. In a few patients seen after five days of paralysis, differences of up to $25 \mu \AA$ in the threshold on the two sides have been followed by complete recovery. If the threshold is "off scale "-that is, over $300 \mu \AA$ on the affected side-denervation is invariable in untreated cases. However, our information on this point is scanty because in such patients the clinical picture has usually been modified.

Anodal galvanic stimulation tests the integrity of the chorda tympani nerve (Taverner, 1965), which leaves the facial nerve at a variable point along its descending course through the mastoid air cells (Anson et al., 1963). The section of nerve running from the geniculate ganglion to a point between the branch to the stapedius muscle and the chorda tympani has a special microscopic structure (Sunderland and Cossar, 1953). This section of the facial nerve forms a single bundle with a dense, thick, perineurial sheath surrounded by a thicker but less dense epineurium merging with the walls of the bony canal. The rest of the nerve consists of a plexus of tiny nerve bundles with many anastomoses. Each small bundle has a thin perineurium and the whole is surrounded by a loose perineurium. It seems from our results that complete recovery is likely when the lesion causing the paralysis is situated distally. In this section of the nerve any swelling of the nerve bundles is con- tained by the perineurium rather than by the bony walls of the Fallopian canal. It is probable that the mid-portion of the nerve, with its dense perineurium surrounding a single, compact bundle of fibres, may be especially liable to internal damage secondary to swelling. This would explain the high liability to denervation when the chorda tympani is invalved (Peiris and Miles, 1965).

The results of A.C.T.H. therapy can be regarded as satisfactory in that the overall incidence of denervation has been reduced by two-thirds and of severe denervation with permanent disfigurement by $90 \%$. There is no evidence that the severity of Bell's palsy has changed spontaneously in recent years. It has been shown that the prognosis is better in younger patients, but the age distribution of the various groups of patients in the present series is exactly the same as in the past. Further improvement is to be expected if treatment is begun on the first day of palsy. This would be justifiable in all cases of severe facial palsy if facilities for anodal galvanic testing are not immediately available.

It is still not clear why A.C.T.H. should succeed when oral corticosteroids fail (Taverner, 1954), but this effect has been noted before in neurological conditions (Miller et al., 1961). A rigorously controlled trial to test this point has now been instituted in this department.

\section{Summary}

The results obtained in the management of 381 consecutive patients with idiopathic infranuclear facial (Bell's) palsy are reported.

Measurement of the threshold for anodal galvanic stimulation established the prognosis for recoverable conduction block with an accuracy of over $90 \%$.

Treatment with A.C.T.H. gel intramuscularly was given to 216 patients. The results in the whole group of 381 patients show a reduction in the overall incidence of denervation by twothirds and of severe denervation by $90 \%$.

We thank Miss L. Lodge and Mr. M. Twitchett for their expert technical assistance. We are indebted to the many doctors who have referred patients so promptly. We are grateful to the chairmen and secretaries of the local health committees in Leeds, Bradford, Barnsley, Dewsbury, and the West Riding for their enthusiastic co-operation.

\section{REFERENCES}

Anson B. Jarper, D. G., and Warpeha, R. L. (1963). Ann. Otol. (St. Louis), 72, 713.

Fearnley, M. E., Rainer, E. H., Taverner, D., Boyle, T. McM., and Miles, D. W. (1964). Lancet, 2, 725.

Krarup, B. (1958). Acta oto-laryng. (Stockh.), 49, 294.

Langworth, E. P., and Taverner, D. (1963). Brain, 86, 465.

Miller, H., Newell, D. J., and Ridley, A. (1961). Lancet, 2, 1120.

Mosforth, J., and Taverner, D. (1958). Brit. med. 3., 2, 675.

Peiris, O. A., and Miles, D. W. (1965). Ibid., 2, 1162.

Sunderland, S., and Cossar, D. F. (1953). Anat. Rec., 116, 147.

Taverner, D. (1954). Lancet, 2, 1052.

- (1955). Brain, 78, 209.

(1959). Proc. roy. Soc. Med., 52, 1077.

(1965). Arch. Otolaryng., 81, 470.

- Fearnley, M. E., Kemble, F., Miles, D. W., and Peiris, O. A. (1966). Brit. med. f., 1, 391. 